\title{
Synthesis of flat-top gain response in fiber phase sensitive amplifiers with improved phase noise regeneration tolerance
}

\author{
Kang, Ning; Seoane, Jorge; Rottwitt, Karsten; Peucheret, Christophe
}

Published in:

CLEO: Science and Innovations, CLEO_SI 2012

Publication date:

2012

Document Version

Publisher's PDF, also known as Version of record

Link back to DTU Orbit

Citation (APA):

Kang, N., Seoane, J., Rottwitt, K., \& Peucheret, C. (2012). Synthesis of flat-top gain response in fiber phase sensitive amplifiers with improved phase noise regeneration tolerance. In CLEO: Science and Innovations, CLEO SI 2012 (pp. CM4N.8). Optical Society of America.

\section{General rights}

Copyright and moral rights for the publications made accessible in the public portal are retained by the authors and/or other copyright owners and it is a condition of accessing publications that users recognise and abide by the legal requirements associated with these rights.

- Users may download and print one copy of any publication from the public portal for the purpose of private study or research.

- You may not further distribute the material or use it for any profit-making activity or commercial gain

- You may freely distribute the URL identifying the publication in the public portal 


\title{
Synthesis of flat-top gain response in fiber phase sensitive amplifiers with improved phase noise regeneration tolerance
}

\author{
Ning Kang*, Jorge Seoane, Karsten Rottwitt, and Christophe Peucheret \\ Department of Photonics Engineering, Technical University of Denmark, DK-2800 Kgs. Lyngby, Denmark \\ kkan@fotonik.dtu.dk
}

\begin{abstract}
We show that flat-top gain responses can be obtained together with two-level flat phase responses in fiber phase sensitive amplifiers by introducing moderate saturation together with dispersion engineering, resulting in an improved phase regeneration performance.
\end{abstract}

\section{Introduction}

All-optical regeneration of phase-shift keying (PSK) signals can be achieved by exploiting the phase squeezing capability of phase sensitive amplifiers (PSAs) utilizing parametric processes in optical fibers [1]. Due to the inherent phase-sensitive nature of the gain, the phase regeneration of such signals is often performed at the expense of phase-to-intensity (PM-to-IM) noise conversion, which also degrades the signal and makes it more prone to nonlinear phase noise further along the link. Combining a phase-regenerator with a phase-transparent intensity regenerator, could solve the problem, at the expense of increased complexity of the regenerator. Alternatively, simultaneous amplitude and phase regeneration has been suggested and demonstrated by operating PSAs in the saturated regime [2-4]. However, such simultaneous regeneration puts some stringent requirements on the amount of phase noise that can be tolerated. Engineering a flat-top gain response while maintaining the desired two-level phase output of the PSA would relieve such a limitation.

In this paper, we report a systematic numerical optimization of the gain and phase responses of dual-pump degenerate-idler PSAs with emphasis on the design of flat-top gain profiles that allow phase-regeneration without inducing excessive PM-to-IM noise conversion. We show that the design target can be reached by operating the PSA in moderate saturation together with proper dispersion engineering. The synthesized PSA response is further shown to result in enhanced phase noise tolerance compared to conventional designs.

\section{Simulation results}
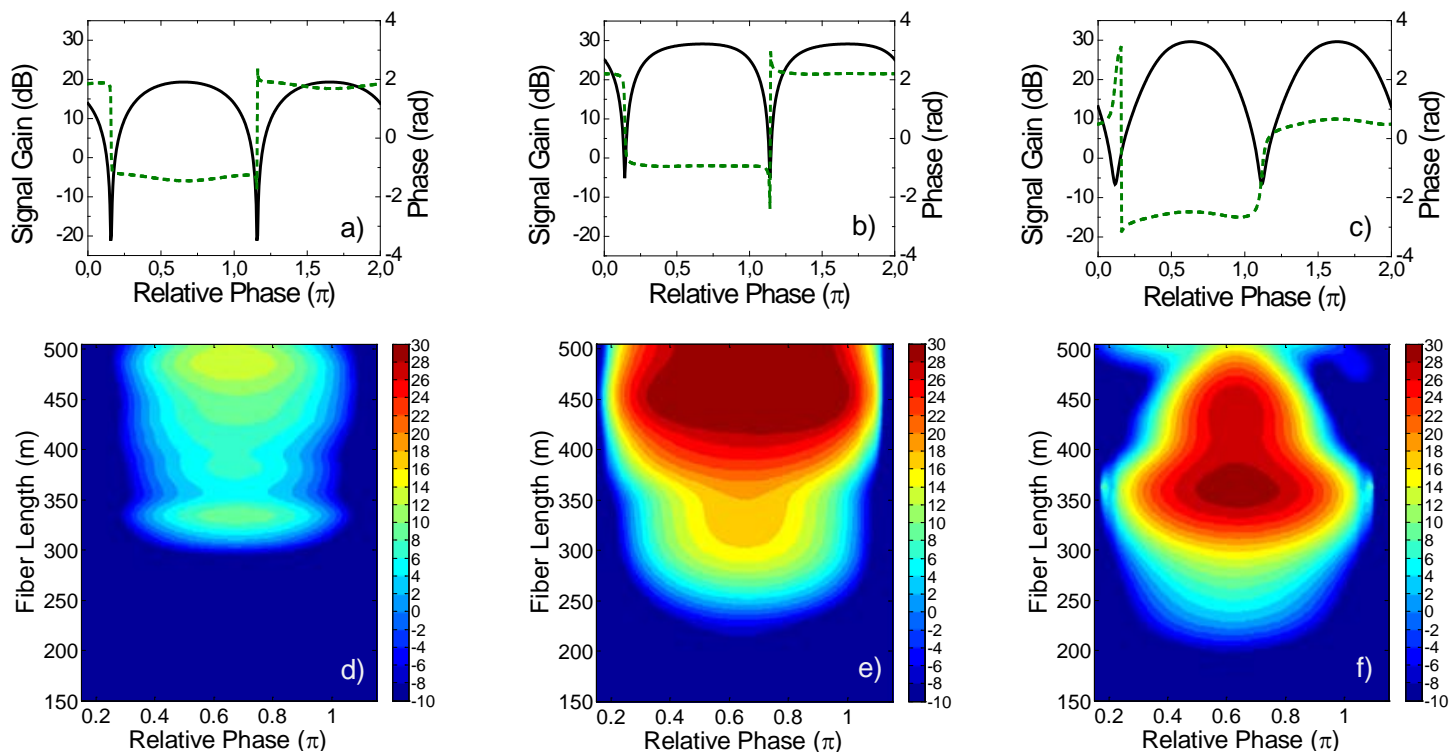

Figure 1 - Top: phase-sensitive gain and phase responses for $400 \mathrm{~m}$ HNLF; Bottom: phase sensitive gain (in $\mathrm{dB}$ ) evolution as a function of fiber length for pump to signal wavelength detunings of $3 \mathrm{~nm}(\mathrm{a}, \mathrm{d}), 4.5 \mathrm{~nm}$ (b,e) and $5 \mathrm{~nm}(\mathrm{c}, \mathrm{f})$. 


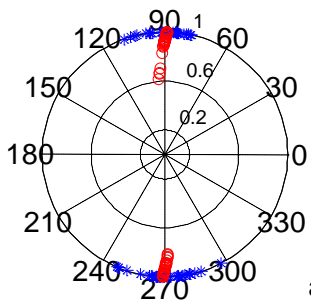

a)

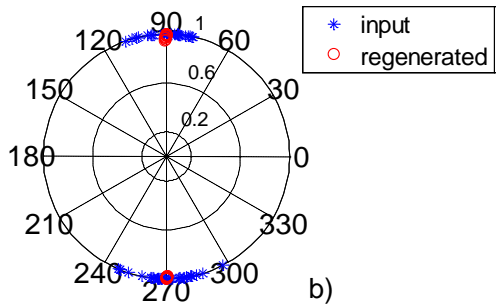

Figure 2 - Constellation diagrams before and after a) phase regeneration by a narrow-top PSA, and b) simultaneous amplitude and phase regeneration by the flat-top PSA. The phase noise standard deviation is $10^{\circ}$.

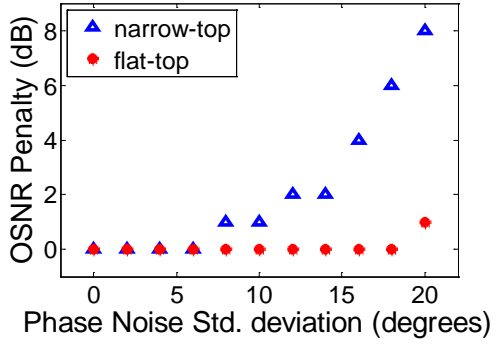

Figure 3 - OSNR penalty as a function of phase noise standard deviation for both narrow-top and flat-top PSAs.

The dual-pump degenerate-idler PSAs investigated in this work are made from a standard HNLF up to 500 m long with zero dispersion wavelength chosen at $1550.39 \mathrm{~nm}$ and dispersion slope, nonlinear coefficient, and loss equal to $0.0185 \mathrm{ps} /\left(\mathrm{nm}^{2} \cdot \mathrm{km}\right), 10.8 \mathrm{~W}^{-1} \cdot \mathrm{km}^{-1}$ and $0.9 \mathrm{~dB} / \mathrm{km}$. The total pump power used is $31.5 \mathrm{dBm}$ and the signal is set to $1560 \mathrm{~nm}$ with $-10 \mathrm{dBm}$ power. The propagation in the HNLF is numerically simulated by solving the nonlinear Schrödinger equation using the split-step Fourier method. It can be seen in Fig. 1 (d-f) that, when the wavelength detuning between the pumps and the signal is set to 3,4 and $4.5 \mathrm{~nm}$, dramatic changes in the shape of the gain profile and its evolution as a function of distance in the HNLF occur. In particular, in the case of a wavelength detuning of $4.5 \mathrm{~nm}$, a flat-top gain covering more than $0.7 \pi$ is obtained, which is furthermore almost invariant with fiber length between 400 and $500 \mathrm{~m}$. The desired two-level phase response is also obtained in this case, as shown for $400 \mathrm{~m}$ long HNLF in Fig. 1(b). In contrast, results reported to date exhibit a narrow-top response such as the one obtained for $3 \mathrm{~nm}$ detuning. It should be pointed out that any deeper saturation would cause the gain curve to acquire a dip in its center portion [5], and at the same time distort the two-level phase function. Such distortions are responsible for insufficient amplitude and phase squeezing performances, and should be avoided in practical implementations for optimum regeneration. The optimum wavelength detuning for achieving flat-top gain can be shown to increase as the fiber dispersion slope decreases. Consequently, our flat-top design relies on the exploitation of moderate saturation together with proper dispersion engineering, the later being a new degree of freedom to be considered for the design of phase sensitive regenerators with low phase-to-intensity noise conversion.

The regeneration properties of the $400 \mathrm{~m}$ long flat-top and narrow-top PSAs are then examined in a system context by simulating their impact on a $40 \mathrm{Gbit} / \mathrm{s}$ differential PSK signal. For this purpose white Gaussian phase noise (PN) is imposed to the signal prior to the PSA. The constellation diagram of Fig. 2(a) confirms the phasesqueezing property of the narrow-top PSA, however at the expense of significant conversion to amplitude noise. In this example, the PN has a standard deviation of $10^{\circ}$. For the same PN amount, the flat-top PSA, on the contrary, shows simultaneous regeneration of both amplitude and phase noise, as shown in Fig. 2(b). The optical signal-tonoise ratio (OSNR) penalty has also been assessed at different PN levels for a bit error ratio of $3.3 \times 10^{-3}$ (Fig. 3 ), confirming the significantly enhanced PN margin of the flat-top PSA.

\section{Conclusion}

Flat-top PSA responses for simultaneous amplitude and phase noise squeezing have been numerically predicted under moderate saturation conditions through proper dispersion engineering. The enhanced phase noise margin of regenerators making use of the proposed PSA responses has also been confirmed, resulting in reduced OSNR penalty over a significantly broader phase noise range than conventional designs.

\section{References}

[1] K. Croussore et al, “All-optical regeneration of differential phase-shift keying signals based on phase-sensitive amplification,” Opt. Lett. 29, 2357-2359 (2004).

[2] A. Bogris et al, "RZ-DPSK signal regeneration based on dual-pump phase-sensitive amplification in fibers,” IEEE Photon. Technol. Lett. 18, 2144-2146 (2006).

[3] K. Croussore et al, "Phase-and-amplitude regeneration of differential phase-shift keyed signals using a phase-sensitive amplifier," Opt. Express 14, 2085-2093 (2006).

[4] R. Slavík et al, “All-optical phase and amplitude regenerator for next-generation telecommunications systems”, Nature Photonics 4, 690-695 (2010).

[5] J. Kakande et al, “Saturation effects in degenerate phase sensitive fiber optic parametric amplifiers,” ECOC, Th.10.C.2 (2010). 